\title{
Impact of HIV on Head and Neck in South India: A Cytology Study
}

\section{Naik Balachandra Ramachandra}

\section{ABSTRACT}

South India is now endemic for human immunodeficiency virus (HIV)/acquired immune deficiency syndrome (AIDS). Government and other organizations statistics are not correlating with our laboratory records. We are getting increased HIV-positive cases for fine needle aspiration cytology (FNAC) at our laboratory. Our past statistics of cytology lesions are altered due to opportunistic infections in HIV-positives, so, we decided to find the real incidences of various opportunistic diseases in HIV-positives pertaining mainly to head and neck only, because, this part of body is the major contributor for our fine needle aspiration cytology workload.

Conducted free ELISA test for all, prior to FNAC procedure to separate immune competent, then study was conducted using available resources in well-planned procedure for definitive diagnosis.

In 1 year, we did 3,407 FNAC, 2,283 (67\%) FNAC cases were belongs to head and neck. We got 359 (10.53\%) HIVpositive patients including 317 (88.3\%) from head and neck, male to female ratio was 1.55:1, cervical lymph node swellings were $89.2 \%$, followed by oral cavity $6 \%$. Youngest patient was 7-year-old and oldest was 54-year, mean age was 26.5 years.

It is very difficult to reduce the incidences and the spread of HIV infection by government/other organizations efforts, needs vigorous effective effort to educate youths of all sections, which is remote for India.

Keywords: HIV endemic in south India is a disaster, Head and neck commonest site, Very difficult to control.

How to cite this article: Ramachandra NB. Impact of HIV on Head and Neck in South India: A Cytology Study. Int J Head and Neck Surg 2012;3(1):11-14.

\section{Source of support: Nil}

Conflict of interest: None declared

\section{INTRODUCTION}

Head and neck is anatomically most complicated structure because of its richness in diverse structures and all these becomes pathological, resulting in mass which may inflammatory or neolpastic. Ninety percent of head and neck masses are diagnosed by initial aspiration. Head and neck aspirates form approximately $65 \%$ of the total workload of cytology. ${ }^{1}$ Neck mass, oral cavity lesions, salivary glands, thyroid and scalp lesions are most commonly encountered visible lesions and easy for FNAC. The spread of HIV in India has been uneven. Although much of India has a low rate of infection, certain places have been more affected than others. HIV epidemics are more severe in the southern half of the country and the far North-East. The highest HIV prevalence is found in Andhra Pradesh, Maharashtra, Tamil Nadu and Karnataka in the South; and Manipur and Nagaland in the North-East. ${ }^{2}$

Extrapulmonary tuberculosis accounts up to 53 to $62 \%$ in HIV-positive cases, cervical lymph nodes are most common site of involvement which is reported in 60 to $90 \%$ patients. ${ }^{3-5}$ Patients may have generalized persistent lymphadenopathy before progressing to AIDS because lymphadenopathy is one of the earliest manifestations of HIV infection. ${ }^{6}$

\section{MATERIALS AND METHODS}

Day by day we are getting more HIV-positive cases at our cytology laboratory for FNAC, so we decided to study the impact of HIV on head and neck, because our laboratory FNAC statistics shows $67 \%$ are from this part. With kind permission of hospital chief, we did free ELISA preliminary test to detect HIV-positives for all those attended our laboratory for FNAC and separated them for our study. Well in advance, we prepared our own clinical and cytological parameters containing case sheets for each HIV-positive and entered our findings. Finally, we made the master chart and come to the conclusion. We did special stains, whenever is needed for microscopic smears free of cost for our study materials. We insisted the HIV-positives to get CD4+ count, but majority refused, because of its cost.

\section{RESULTS}

In 1 year, we did 3,407 FNAC, which includes 2,283 (67\%) from head and neck. Among all, 359 (10.53\%) were HIVpositive and of these, head and neck constitutes 317 (83.3\%). Pertaining to head and neck, youngest patient was 6 years old and the oldest was 54. Mean age was 26.5 years and male to female ratio was $1.55: 1$, all these patients were appeared to be belong to all sections of society, it is very difficult for us to divide them on socioeconomic status. Commonest pathological mass in head and neck was cervical lymph node swellings (89.2\%) which is followed by oral cavity (5.99\%) (Fig. 1).

Tubercular lymphadenitis with Langhans giant cell, caseous necrosis, along with acid-fast bacilli was found in 148 (46.68\%), followed by reactive lymphadenitis in 79 (24.9\%) cases. Caseous necrosis only was seen in 13 (4.1\%) (cytology microphotograph 1), of these two had their 
No. of cases

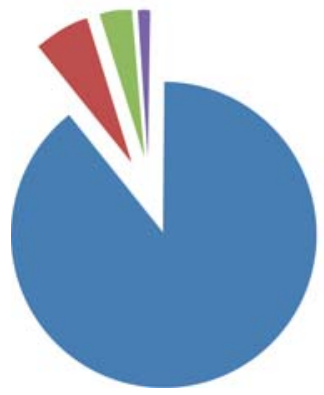

Fig. 1: Percentage of FNAC done from head and neck various sites

No. of cases

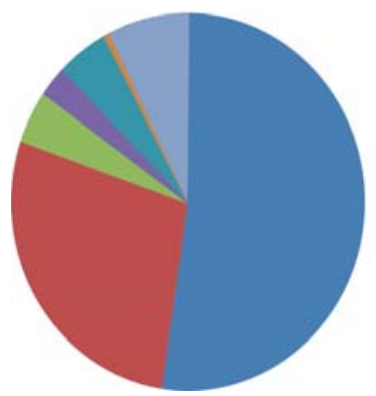

TB lymphadenitis

Reactive hyperplasia

$\square$ Caseous necrosis

口 Lymphoma

Secondary metastasis

Granulocytic sarcoma

$\square$ Undiagnosed

Fig. 2: Number of HIV-positives having various diseases diagnosed by FNAC on head and neck

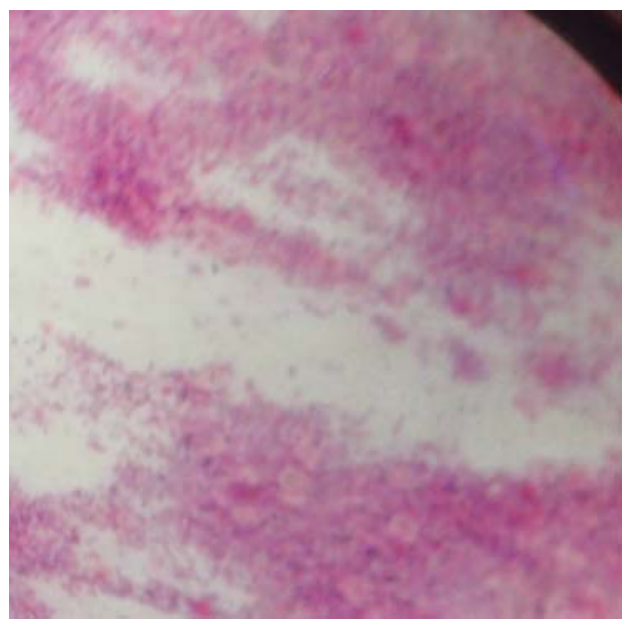

Fig. 3: Cytology microphotograph 1 of tubercular lymphadenitis of HIV-positive having CD4+ count 250 shows presence of eosinophilic granular (caseous) necrosis only

CD 4+ count 250 and 200. Majority oral cavity manifestations were due to fungal infections, seen in nine cases (Fig. 5), followed by leukoplakia in seven cases and two cases had squamous cell carcinoma of cheek (Fig. 7). NonHodkins lymphoma was seen in six patients and metastasis of squamous cell carcinoma was found in seven patients. We were unable to come to conclusion for 22 (6.94\%) diagnosis (Fig. 2), so advise these for histological confirmation (Figs 3, 4 and 6). Majority of thyroid and parotid lesions were inflammatory and were not specific for HIV infection.

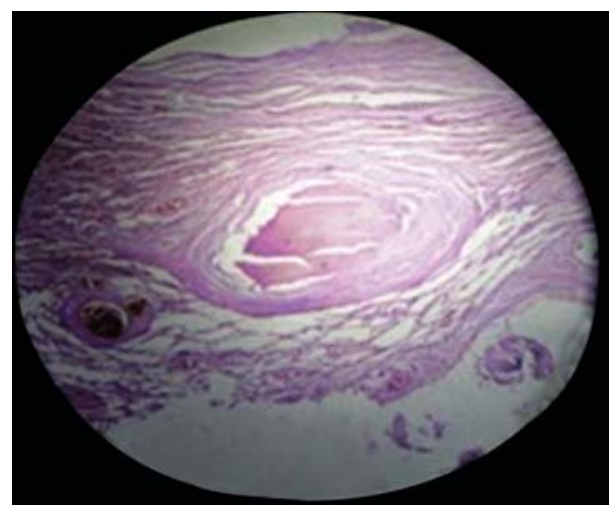

Fig. 4: Histopathological microphotograph 1, right supraclavicular mass in HIV-positive was unable to diagnose by FNAC, biopsy taken and shows presence of Cryptococcus globi, which were stained by PAS special stain

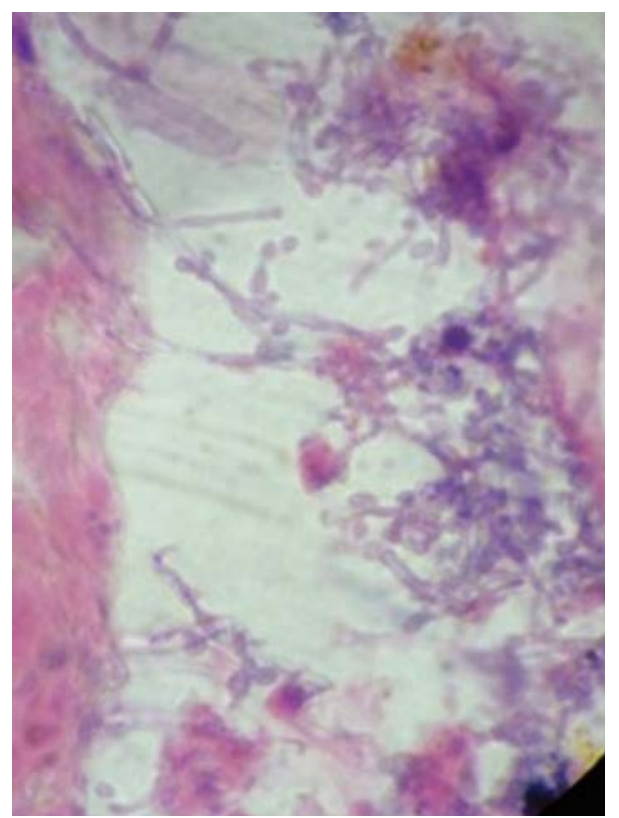

Fig. 5: Cytology microphotograph 2 of mucosal scrap of patient with intraoral ulcer showing fungal infection (Candidiasis stained with $\mathrm{H} \& \mathrm{E}$ showing branching pattern hyphae)

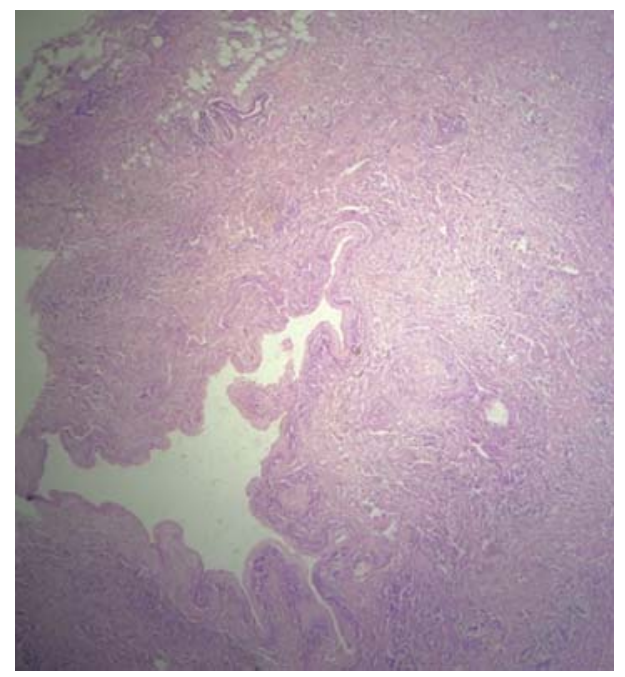

Fig. 6: Histopathology microphotograph 2 from parotid swelling in HIV-positive was unable to diagnose by FNAC, because only inflammatory fluid we got, so advised for biopsy, this photomicrograph shows presence of cysticercosis-a parasite 


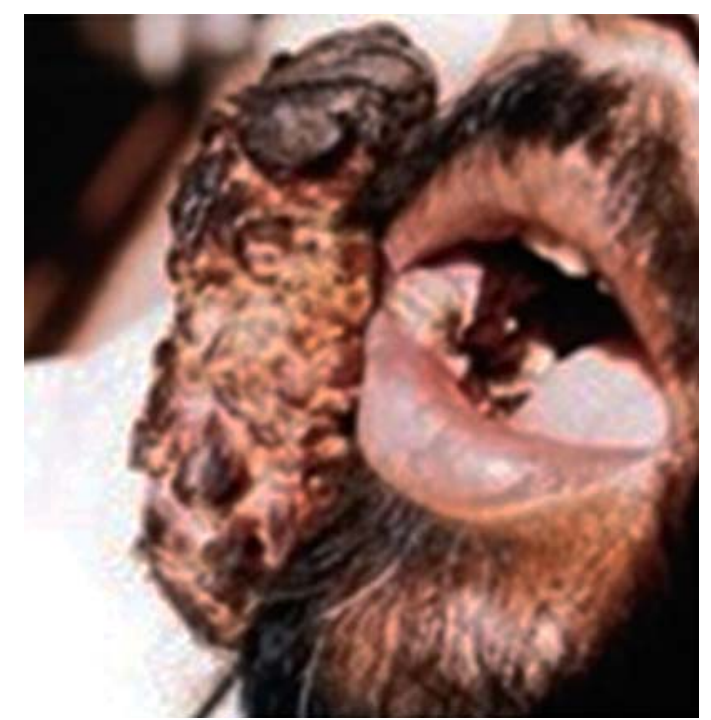

Fig. 7: A 54-year-old HIV-positive having squamous cell carcinoma of buccal mucosa

\section{DISCUSSION}

Dr Rajan Gupta a nuclear physicist at Los Alamas National laboratory in the USA, deeply concerned at the spread of AIDS in India and warned of a disaster. ${ }^{2}$ Now, the above words appearing nearly true, because during past years many cytology studies were conducted in India, on impact of HIV, but those are of more than year duration and got less number of HIV-positive cases, that is in double digits, now within 1 year we got HIV-positives in 100 (359), which indicates there is rapid rise in the incidences of HIV positives coming to the cytology laboratory with swelling on body. Shenoy $\mathrm{R}$ et $\mathrm{al}^{7} 2002$ and Sujata Naik et $\mathrm{al}^{8} 2003$ studied HIVpositive cervical lymph nodes, 48 and 25 cases respectively and the same is compared with our present study (Table 1), it found that there is variation in the statistic because that defends on duration HIV infection in each cases.

HIV infection invites opportunistic infections due to reduction in immunity and people infected with HIV have greater risk of developing malignancy like Kaposi's sarcoma, non-Hodgkins and Hodgkins lymphoma and oral cancer more common in head and neck. ${ }^{9}$

Grulich, Andrew et al studied linkage of HIV, AIDS and cancer, they found increased rate of lip cancer, Hodkins disease, myeloma and leukemia in patients less than 5 years prior to development of AIDS. ${ }^{3}$

L Barzen et al in 1993, studied retrospective 210 HIVpositive patients for ENT evaluation and found enlarged nodes in neck, neck mass, nasopharyngeal lymphatic tissue hypertrophy, oral leukoplakia and candidiasis. Overall 84\% patients had head and neck lesion manifestations. ${ }^{4}$

Samaila and Oluwale OP analyzed their 9 years retrospective study on FNAC of cervical lymph node, among these 48 were from HIV-positive cases and all these had cervical lymphadenopathy and they concludes that mean age of these patients was 27 years, microscopically, they found granuloma in all, but acid-fast bacilli found in 23 (48\%) cases. $^{5}$

The presence of specific oral manifestations and the number of different concurrent intraoral lesions among HIVinfected persons are associated with severe immune suppression and AIDS. Oral examinations are an essential component for early recognition of disease progression and comprehensive evaluation of HIV-infected patients. ${ }^{10}$

Candidiasis was the most common oral lesion, followed by hairy leukoplakia. Kaposi's sarcoma, melanotic macules, herpes labialis, condyloma acuminatum, perioral molluscum contagiosum, and bacterial glossitis due to Escherichia coli infection were found in a small number of patients. Results of culture for fungi, available for 203 patients, revealed that $51 \%$ of patients with positive Candida cultures had clinical evidence of candidiasis. ${ }^{11}$

Oral mycoses in HIV infection are becoming increasingly common. Of these, oral candidiasis is by far the most prevalent; oral candidiasis is one of the earliest premonitory signs of HIV infection. ${ }^{12}$

In the year 1993, Kent Bottles et al studied 121 HIVseropositive/AIDS patients lymph node FNAC and found,

Table 1: Comparative analysis of lymph node studies in HIV-positive patients

\begin{tabular}{|c|c|c|c|c|c|}
\hline Author and period & $\begin{array}{l}\text { Tubercular lymphadenitis } \\
\text { percentage }\end{array}$ & $\begin{array}{l}\text { Reactive lymph- } \\
\text { adenitis percentage }\end{array}$ & $\begin{array}{l}\text { Acid-fast bacilli } \\
\text { negative percentage }\end{array}$ & $\begin{array}{l}\text { Malignancy } \\
\text { percentage }\end{array}$ & $\begin{array}{l}\text { Undiagnosed } \\
\text { percentage }\end{array}$ \\
\hline $\begin{array}{l}\text { Shenoy R et al } \\
\text { 2002, studied } \\
48 \text { HIV-positives }\end{array}$ & 48 & 36 & 2 & 2 & 13 \\
\hline $\begin{array}{l}\text { Sujata Naik et al } \\
2003 \text {, studied } \\
48 \text { HIV-positives }\end{array}$ & 60 & 40 & 28 & 28 & 0 \\
\hline $\begin{array}{l}\text { Present study } \\
2011,317 \text { HIV- } \\
\text { positives }\end{array}$ & 46 & 24.9 & 4.1 & 6.62 & 6.94 \\
\hline
\end{tabular}


60 (50\%) hyperplasia, 24 (20\%) non-Hodgkin’s lymphoma, 21 (17\%) mycobacterial infection, 12 (10\%) cases of Kaposi's sarcoma and one each of Hodgkin's disease and giant cell carcinoma, interesting is no false-positive results occurred in this series. ${ }^{13}$ In the year 2008, SM Lowe et al studied 73 HIV-positive patients after highly active antiretroviral therapy (HAART) treatment and found that there is change in the spectrum of diseases. ${ }^{14}$ Now, HAART is available and it is not only costly for common man in India, but also it has got more severe side effect on our all vital organs, so life of HIV-positives are under question mark. Rajan Gupta, given the current conservative number of HIV-positive individuals (UNAIDS) estimated five million HIV-positive people in India at the end of 1998 and doubling every 2 to 3 years, means that will be 50 million by 2007 and 100 million by 2010, that is one in 10 people ( 1 in every family which is seen in all socioeconomic level). ${ }^{2}$

\section{CONCLUSION}

Majority of youths in India are not following the advice of their own parents, will they follow government/other organizations advice? They are enjoying the unsafe sexual life to invite this dreaded virus. Government and other organizations are trying their level best to control the spread, but, it is not effective, so, India has to face the consequences (we should not forget that healthiest nation is one which harbors healthy citizens). HIV infection is pandemic, many countries in the west controlled its spread by taking strong decisions by educating the citizens. Will India achieve it? and prevents the spread of this dreaded virus?

\section{REFERENCES}

1. Chinoy R. Otorhinolaryngology clinics: An International Journal, January-April 2010;2(1):25-32.

2. Jayasekara D. World socialist Web Site-WSWS.Org. Published by the international committee of the fourth international (ICFI).

3. Grulich, Andrew, et al. AIDS 24 May 2002;16(8): 1156-61.

4. Barzon L, et al. The Journal of Laryngology and Otology 1993;107:133-36 (online published; 29 June 2007).

5. Samaila M, Oluwole OP. Niger J Clin Pract July-Sept 2011;14(3):297-99.

6. Jayaram G, Chew MT. Fine needle aspiration cytology of lymph nodes in HIV-infected individuals. Acta Cytol 2000;44:960-66.

7. Shenoy R, et al. Acta Cytol Jan-April 2002;46(1):35-39.

8. Sujata Naik, et al. Cytopathol 2003;29:146-48.

9. Joel B, et al. Oral Surgery, Oral Medicine, Oral Pathology February 1992;73:103-200.

10. Glick M, et al. Oral Surgery, Oral Medicine, Oral Pathology April 1994;77(4):344-49.

11. Baronr R, et al. Oral Surgery, Oral Medicine, Oral Pathology February 1990;69(2):171-73.

12. Lakshman P, et al. Oral Surgery, Oral Medicine, Oral Pathology February 1992;2:171-80.

13. Bottles K, et al. J Clin Pathol 1993;46:564-66.

14. Lowe SM, et al. International Journal of STD and AIDS August 2008;19:553-56.

\section{ABOUT THE AUTHOR}

\section{Naik Balachandra Ramachandra}

Associate Professor, Department of Pathology, Vinayaka Mission's KV Medical College, Salem, Tamil Nadu, India

\section{CORRESPONDING AUTHOR}

Naik Balachandra Ramachandra, Residence No-85, Madhura Chetana Colony, Kusugal Road, Keshwapur, Hubli-580023, Karnataka India, Phone: 09597213022, e-mail: drnbr.57@gmail.com 